\title{
A relação entre o espaço e a saúde bucal coletiva: por uma epidemiologia georreferenciada
}

\author{
The relation between space and collective oral health: \\ for a georeferenced epidemiology
}

Rafael da Silveira M oreira ${ }^{1}$

Lucélia Silva $\mathrm{N}_{\text {ico }}{ }^{1}$

Nilce Emy Tomita ${ }^{2}$

'Departamento deSaúde

Pública. Faculdadede

M edicina deBotucatu.

Universidade Estadual

Paulista. Distrito de Rubião

Júnior, s/n. 18618-970

Botucatu SP.

moreirars@bol.com.br

${ }^{2}$ Departamento de

Odontopediatria,

OrtodontiaeSaúde

Coletiva. Faculdade de

Odontologia deBauru.

Universidade deSão Paulo.
Abstract The influence of the environment on health is an ancient human concern. From the Hippocratic texts to today, the concept of space permitted and still permits different representations and forms of perception. Overcoming the natural conception of space as only an inert and passive environment, the idea of a socially constructed geographic space, both as a receiver of social processes as much as being its own activator in these processes, becomes ever more relevant in the comprehension of phenomena involved in the health-disease process. In this sense, epidemiology is presented as a privileged reference point in the articulation of place time people elements. This reflexive investigation seeks to explore the relations established between space (social and geographical) and Collective O ral H ealth, emphasizing the role of territory in the reproduction of iniquities in health and the necessity of developing studies that approach space as a constitutive element in theoral health-disease process. In what could betermed a georeferenced epidemiology, the spatial expression of events of oral health-disease and of the actors involved in this process strengthens the importance of territory (and its various significations) to Collective $\mathrm{O}$ ral $\mathrm{H}$ ealth. Key words Oral Health, Epidemiology, Geographic Information Systems
Resumo A importância do meio-ambiente sobre a saúde das pessoas é uma preocupação antiga do ser humano. Dos textos hipocráticos aos dias de hoje, o conceito de espaço permitiu e permite dife rentes representações eformas de apreensão. Superando a concepção natural do espaço apenas como um ambiente inerte e passivo, a visão de um espaço geográfico socialmente construído, tanto como um receptor dos processos sociais quanto como 0 próprio ativador destes processos, torna-se cada vez mais relevante na compreensão dos fenômenos envolvidos no processo saúde doença. N este sentido, a epidemiologia seapresenta como um referencial privilegiado na articulação entre os el ementos lugar-tempo-pessoas. Este ensaio reflexivo busca explorar as relações estabelecidas entre o espaço (social egeográfico) ea Saúde Bucal Coletiva, destacando o papel do território na reprodução das iniqüidades em saúdee a necessidade do desenvolvimento de pesquisas que abordem o espaço como elemento constitutivo do processo saúde-doença bucal. A proximando-se do que poderia ser chamado de uma epidemiologia georreferenciada, a expressão espacial dos eventos de saúde doença bucal e dos atores envolvidos neste processo fortalece a importância do território (e suas várias significações) para a Saúde Bucal Coletiva. Palavras-chave Saúde Bucal, Epidemiologia, Sistemas de Informação Geográfica 
Introdução

A influência do meio ambiente sobre as condições de saúde das pessoas é uma preocupação antiga do ser humano. Ainda no século $\mathrm{V}$ a.C. Hipócrates já defendia a importância do espaço como o lócus de ocorrência das doenças em sua obra, pioneira neste aspecto, D os ares, dos mares e dos lugares ${ }^{1}$.

Séculos depois, o médico britânico J ohn Snow iniciava um importante passo na compreensão de como a distribuição de eventos de saúde-doença no espaço poderia fornecer hipótese etiológica para a sua ocorrência. Pelo uso sistematizado de uma metodologia científica e com a realização deuma investigação epidemiológica, Snow contribuiu para o fim da epidemia de cólera na cidade de Londres, em 1854, por meio da associação espacial entre mortes por cólera e o fornecimento de água em diferentes bombas de abastecimento público².

Apesar de a epidemiologia ainda ser uma ciência relativamente nova, ela possui um conjunto próprio de metodologias de investigação em saúde. Notadamente após a Segunda Grande Guerra, vários estudos epidemiológicos passaram a exercer grande influência na saúde das populações. Como exemplo, os ensai os comunitários de suplementação de flúor nas águas de abastecimento público, que seiniciaram durante a década de 1940, difundindo uma forma de prevenção primária da cárie ${ }^{3}$. A identificação de re gi ões com diferentes concentrações de flúor pre sente naturalmente na água tem mostrado repercussões sobre a prevalência e severidade de cárie dentária, evidencian do a influência ambiental sobre a saúde bucal da população.

A distância secular presente nos estudos acima mencionadoséreduzida pela importânciaque eles atribuíram ao espaço como um fator determinante para a ocorrência de eventos de saúde ou doença. Nesta perspectiva, o meio ambiente deixou de ser apenas um pano de fundo ou um simples cenário onde seus protagonistas (população) adoeciam para se transformar em ator atuante nesse processo, ou seja, um agente com poder de provocar mudanças significativas nos perfis de morbimortalidade de uma sociedade.

A evolução da própria Epidemiologia, reve lando um potencial epistemológico e metodológico para se postular como Ciência da Saúde e e e reconhecimento de uma necessidade de se buscar transformações estruturais que desequilibrem 0 sistema desencadeante das iniqüidades, ao invés de apenas propor medidas corretivas biológico- ecológicas ${ }^{5}$, reforçam a validade de uma estraté gia conceitual e metodológica que tenha como perspectiva a abordagem do espaço geográficosocial entendido como expressão das condições de vida da população ${ }^{6}$.

Sob esta perspectiva, a Saúde Bucal Coletiva, dentro dos limites de uma reflexão que a considereum novo paradigma, mas reconhecida como um campo aberto ao debate não-dogmático e não-normativo ${ }^{7}$, poderá encontrar na espacialização do processo saúde-doença bucal uma relação entre ocorrências edeterminantes, adotando a epidemiologia como referencial privilegiado no estudo desta relação.

\section{A relação entre o espaço ea saúde ea construção social destes dois elementos}

O conceito de espaço é, ao mesmo tempo, uma questão antiga erecenteno discurso científico de momentos históricos distintos. Assim como todos os conceitos e "ciências", sua definição é derivada da luta constante entre diferentes correntes filosóficas, próprios deum determinado momento histórico, na busca pela solução (provisória) dos problemas impostos pelos paradigmas dominantes de cada época. $\mathrm{Na}$ discussão sobre a existência de um mundo real eum mundo percebido, M erleau-Ponty destacava o espaço não como uma realidade em si nem uma qualidade das coisas, mas o modo como o sujeito corpóreo constrói sua experiência do mundo. N este sentido, "o espaço não é o meio, nem físico nem lógico, onde as coisas se posicionam, mas aquilo que permite posicioná-las"8.

Partindo desta abstração do espaço, o pensamento kantiano também sustentava a existência do espaço de forma apriorística, ou seja, não como o resultado da ação humana, mas, sim, um prérequisito para esta ação humana, sendo impossível imaginar que os objetos se apresentassem fora do espaço ${ }^{9}$. Dessa forma, o espaço passaria a existir independente de nossos sentidos ou ações, mas como o modelador destes dois elementos.

A existência de várias representações do espaço permite variadas concepções a seu respeito. Sendo assim, a escolha de um determinado conceito se dará em função do pragmatismo de sua abordagem. Da mesma forma como nossos sentidos não são capazes de apreender o mundo em sua totalidade, forçando-nos a construir modelos que expliquem a realidade, os mapas constituem modelos explicativos e representativos do 
mundo real, mais especificamente do espaço real. Além do próprio aspecto reducionista queacompanha o conceito de modelo, $\mathrm{M}$ iceli ${ }^{10}$ destaca a importância política da cartografia na disseminação de ideologias dominantes. 0 modo como as partes do mundo são representadas e ilustradas traz consigo os ideais de superioridade de uma determinada nação em detrimento de outras. Ilustrando o caráter político da representação do espaço, 0 autor apresenta um texto contido em um atlas datado de 1574:

"[...] em posição proeminente encontramos a Europa [...] Está retratada com vestes de soberana, com coroa e cetro e segura um globo imperial que simboliza claramente a hegemonia das potências católicas. À esquerda, uma princesa oriental ornada dejóias, com um turíbulo de incenso, personifica a Ásia das especiarias; em frente, do outro lado, a África tem 0 aspecto de uma negra pobremente vestida, à qual meteram na mão um raminho de bálsamo, a santa planta deN ossa Senhora, quefloresce, apenas, num jardim egípcio. A América reconhece se na mulher impudicamente nua quejaz embaixo, com uma cabeça de homem cortada na mão e brandindo uma clava, a indicar que se alimenta de carne humana e que vive no estado de 'natura', isto é, na ignorância de qualquer forma de organização civil e política."

Não obstante, uma concepção marxista do espaço (objeto) o admitiria como o resultado da ação do homem (sujeito), sendo esta ação humana também influenciada pelo próprio espaço em uma sociedade contraditória, marcada pelo conflito de classes. Dessa forma, materializa-se na questão do espaço a abstração típica das Ciências Sociais envolvida nas relações entre o sujeito e o objeto, elementos que fundamentam a metodologia científica ocidental. Com efeito, "teoria e prática científica também constroem representações simbólicas sobre o espaço e estruturam distintas formas de apreensão e de ação sobre a realidade" 11 .

Barrios $^{12}$ destaca que a adaptação ativa do ser humano no espaço, não mais simplesmente ocupado ou aproveitado (adaptação passiva), mas transformado, fruto da evolução das próprias formações sociais, compreende não apenas a produção de bens materiais, mas também a adequação do meio ambiente circundante às necessidades individuais, familiares, comunitárias e das formações sociais em seu conjunto.

Neste sentido, D onnangelo $0^{13}$ destaca a participação da prática médica na reprodução das estruturas político-ideológicas por meio da manutenção da força de trabalho e controle das tensões e dos antagonismos sociais ( características que "capitalizaram" a medicina e seu produto). Dessa forma, torna-se coerente cogitar a participação do processo saúde-doença na construção social do espaço, determinando, em parte, suas transformações físicas e ideológicas.

Tais afirmações se aproximam dos conceitos geográficos propostos por Milton Santos sobre a organização social do espaço como uma produção histórica advindo das relações nel eestabelecidas. Com efeito, as diferentes formas de inserção social refletem não apenas a desigual distribuição territorial, mas diferentes perfis epidemiológicos ${ }^{11}$.

Costa e Teixeira ${ }^{6}$ ressaltam que a aproximação entre o saber médico ea geografia, após a era hipocrática, foi impulsionada com os grandes descobrimentos, que demandavam conhecer as doenças nas terras conquistadas para proteger os colonizadores e as atividades comerciais, configurando o que seria, posteriormente, o celeiro da M edicina Tropical. 0 desenvolvimento da M icrobiologia, privilegiando o agente etiológico, relativizou o papel da natureza, tornando-a apenas um fator secundário, estagnando a discussão sobre a influência espacial no processo saúde-doença.

A superação do paradigma da unicausalidade, representada pelo avanço da teoria da multicausali dade, como a tríade ecológica de Leavell \& Clark centrada no hospedeiro-agente-ambiente, representou um avanço considerável, porém, insustentável com o crescente desenvolvimento da Epidemiologia Social, tendo a contribuição marxista de Jaime Breilh especial influência sobreos estudos epidemiológicos nos países da América Latina.

Neste sentido, o modelo de Leavell \& Clark passou a ser criticado por reduzir as ações de saúde apenas sobreos elementos da tríadeecológica hospedeiro-agente-ambiente, ignorando a categoria social do homem, transformando- 0 em um "fator eminentemente biológico". Dessa forma, propunham-se medidas corretivas biológico-ecológicas e em nenhum momento buscavam-se transformações estruturais que atentassem contra o equilíbrio do sistema ${ }^{5}$.

De certa forma, a epidemiologia, como ciência, vive hoje um momento detransição. A hegemonia dos estudos "individuados" - terminologia didaticamente utilizada por Almeida-Filho ${ }^{4}$ para indicar estudos com abordagens individuais, diferenciando-os dos estudos agregados ou ecológicos - e do uso de modelagens estatísticas cada vez mais sofisticadas parecem estar sendo 
abalados pela não incorporação do espaço na dinâmica do processo saúde-doença ou, quando incorporado, passa a ser apenas mais uma variável individual, assim como tantas outras que, equivocadamente, julga-se ser a sua soma o sinônimo de coletivo. A própria fragmentação da Epidemiologia, a exemplo da fragmentação do coletivo em variáveis, contribui para seu enfraquecimento como ciência.

No entanto, a recente valorização dos estudos ecológicos (ditos de "segunda linha") surge como um caminho na incorporação de fenômenos socioespaciais envolvidos no processo saúde-doença. Porém, refinamentos metodológicos são necessários deforma a não simplificar a complexidade destes fenômenose, assim, reproduzir a noção estática e isolada do espaço.

\section{A saúde bucal ea sua expressão espacial}

A pesar dos avanços no tratamento da cárie, antes apoiado na amputação dos tecidos (muitas vezes com extensões preventivas) ehojeconsolidado sob o paradigma da microbiologia ${ }^{14}$, possi bilitando intervenções precoces na restauração do tão desejável equilíbrio desremineralização do esmalte dentário, a O dontologia ainda se mostra incapaz de resolver os problemas bucais de grande parte da população brasileira. Parte dessa incapacidade é explicada pelo fato de que os fatores envolvidos na gênese das doenças bucais são tratados como determinantes independentes.

Os avanços técnico-científicos não apresentam repercussão de maneira igual entre as diferentes classes sociais. 0 paradigma biologicista, hegemônico na prática odontológica, insiste em controlar as doenças bucais baseando-se na limitada tríadeecológica de Leavell \& Clark. N este sentido, substituíram-se as formas de tratamento, mas sem que houvesse uma reflexão sobre as origens sociais, muitas vezes reduzidas nas variáveis renda e escolaridade.

Aproximando-se do modelo da rede causal ou "teia de causação", emprega-se um tipo de bal ança quenivela todas as distinções. Dessa forma, a variável acesso ao tratamento clínico e a variável econômica ocupam um mesmo nível, sofrendo a mesma ponderação?

A análise conjunta de variáveis individuais e variáveis ecológicas corrobora a idéia de investigação em múltiplos níveis, levando-se em conta a hierarquia decomplexidade eas múltiplas interações entre os diferentes níveis, vislumbrando o que é denominado por Susser e Susser ${ }^{15}$ como uma eco-epidemiologia. Esta corrente teórica também édenominada por Krieger ${ }^{16}$ como "ecossocial", uma metáfora capaz de integrar os conhecimentos biológico e social correspondendo a uma estrutura de um objeto de natureza fractal, com a inter-relação das diversas variáveis em todos os níveis, do molecular ao social, respondendo à fragmentação desconecta entre as várias epidemiologias. M oysés e Sheiham ${ }^{7}$ sugerem a adoção destas correntes interativas e em múltiplos níveis como um novo paradigma para a Epidemiologia predominando uma sócio-ecoepidemiologia.

Neste sentido, a superação da falácia “individualista" (suposição de que dadosindividuais são suficientes para explicar fenômenos grupais) e da falácia ecológica (atribuição de riscos individuais a partir de dados grupais) seria viável por análises contextuais, ou análise em multiníveis, combinando dados individuais e de grupo ${ }^{7}$.

A aparente ten dência da concentração de várias doenças em áreas urbanas pobres, muitas vezes, dentro da mesma cidade, tem sido denominada na literatura como "diferenciais intraurbanos em saúde". No entanto, M oysés e Sheiham ${ }^{7}$ nos provocam a reflexão a partir da indagação " (se) os efeitos refletem exclusivamente as características dos próprios indivíduos, dentro das áreas, o que é chamado efeito composicional, ou refletem também a expressão da própria área, um efeito contextual?" Talvez esta provocação gere uma contenda filosófica cujo desfecho não necessariamente represente o cerne da questão. Antes, é desejável que esse dilema seja superado pela existência dialética entredeterminantes individuais e ecológicos, visto a impossibilidadedese separar o indivíduo de seu território.

Porém, torna-se imprescindível destacar a relação temporal da experiência do indivíduo com seu território. A simples descrição das condições de saúde bucal de uma pessoa e sua relação com sua posição geográfica não é, per se, determinante no processo saúde-doença. Principalmente quando consideramos que a cárie ea doença periodontal, especialmente em idosos, são resultados cumulativos de vários anos em que cada indivíduo foi submetido a diferentes níveis de exposição, tanto a fatores de risco quanto a fatores de proteção, não necessariamente tendo ocorrido em um mesmo ambiente ao longo da vida. Em contrapartida, reconhecemos uma reprodução, de expressão espacial, das condições de vida e saúde da população na medida em que o local demoradia do indivíduo refletesua própriacon- 
dição socioeconômica. Dessa maneira, o território, como reflexo das condições econômicas de seus habitantes e sujeito às iniqüidades sociais e políticas, poderia influenciar negativamente as condições de vida de seus ocupantes. Percebe-se, então, que o território passa a gerar (e gerir) a pobreza de forma sustentável.

O território se configura em uma dimensão constitutiva da situação em que se encontram os diferentes grupos sociais na cidade, especialmente entre os mais pobres. M arques e Torres ${ }^{17}$, partindo desta premissa, afirmam que "indivíduose famílias igualmentepobrese escolarizadostêm condições e características diferentes dependendo de onde morem". N este sentido, "o próprio espaço, ao contrário de ser apenas um produto desses el ementos, representa também um conjunto de constrangimentos e possibilidades, diferenciando as oportunidades que moradores de lugares mais ou menos segregados experimentam" ${ }^{17}$. As pessoas se movimentam em espaços físicos cujas características interagem com suas potencialidades, tendo em vista as limitações apontadas pelas fronteiras físicas, sociais e simbólicas do território ${ }^{18}$.

Com efeito, ações em saúde devem ser pensadas, articuladas e executadas de forma intersetorial. Acreditar que medidas somente no campo da saúde bucal serão capazes de resolver as iniqüidades na distribuição do processo saúde-doença é um discurso análogo àquele que afirma ser o papel da Odontologia apenas o de cuidar dos dentes. Quando consideramoso espaço onde as doenças e agravos à saúde são produzidos, compreendemos o impacto que ações "extrabucais" podem gerar nas condições de vida da população e em sua saúde.

Neste aspecto, concordando com Gomes e Amitrano ${ }^{19}$, as variáveis tradicionais normalmente utilizadas, tais como renda, escolaridade, sexo, grupo etário e grupo étnico, sem a incorporação de atributos territoriais, não são "capazes de captar as variações nas condições de vida e de bemestar de populações que têm perfis sociais seme Ihantes, mas residem em lugares distintos."

Assim é que defendemos a premissa de que indivíduos com perfis sociais semelhantes (renda, escolaridade, sexo, grupo etário, grupo étnico, entre outros) podem apresentar diferentes níveis de saúde bucal, dependendo do seu local de moradiae dos atributos desselocal. Indo mais além, as chances de um indivíduo possuir uma boa saúde bucal podem estar associadas não apenas ao seu local de moradia, mas também aos lugares por onde esse indivíduo transita em sua experiência coti diana de vida. Da mes- ma maneira que a reprodução marginal das precárias condiç̧ões de vida sustenta o "círculo vicioso da pobreza", é coerente afirmarmos a existência de um "círculo vicioso do processo saúde-doença bucal" determinado não só por aspectos individuais, mas também por aspectos coletivos como o local de residência e as relações (de vizinhança ou não) estabelecidas no "território vivido".

Aspectos geográficos podem estar relacionados de diferentes formas com aspectos da saúde bucal da população. Dentreestes, podemos apontar a própria condição de saúde bucal, a localização de serviços de atenção odontológica e as formas deacesso a esses serviços (locomoção etransporte), a localização de equi pamentos sociais (escolas, centros comunitários e áreas de lazer), a infra-estrutura local como provedora de condições mínimas de bem-estar para a população (saneamento básico, energia elétrica, moradias adequadas e segurança pública) e toda a rede de suporte social. Em se tratando de idosos, por exemplo, 0 isolamento territorial podeser determinanteno acesso a serviços odontológicos, principalmente quando consideramos o grau de dependência destes idosos.

Em termos gerais, poucos são os estudos que procuraram abordar a relação entre 0 espaço geográfico e a saúde bucal. A preocupação em localizar geograficamente as condições de saúde bucal iniciou-se paralelamente com a preocupação em gerar informações epidemiológicas que pudessem ser padronizadas e que permitissem comparações entre diferentes regiões do mundo. Por meio de ferramentas da cartografia e com a ascensão da "Geografia das Patologias" iniciada na década de 1940, os estudos epidemiológicos em saúde bucal se reduziam ao mapeamento da cárie em várias partes do mundo, apenas como uma forma descritiva e gráfica de apresentação dos dados disponíveis sobre a cárie ${ }^{20}$. A idéia era de somente "colorir" os mapas de acordo com um ranking estabelecido sobre a cárie em diferentes países.

Análise espacial em saúdebucal: a epidemiologia georreferenciada

A Epidemiologia se empenha em compreender a distribuição de doenças ou agravos à saúde em coletividades humanas. Dessa forma, os epidemiologistas questionam se existe algum padrão na distribuição da doença no espaço, se há alguma associação com alguma fonte etiológica (água, 
poluição atmosférica eviolênciaurbana, por exemplo), se há alguma evidência de transmissão e se houve variação no tempo. Pessoas, lugar e tempo constituem a tríade básica da produção einterpretação dos constructos epidemiológicos, podendo ser escrita como pessoas em lugares/tempo, evidenciando o papel fundamental do espaço (físico e histórico) na ocorrência de eventos em saúde ${ }^{21}$.

A visualização da distribuição da tríade epidemiológica no espaço e a tradução dos padrões existentes nesta distribuição vêm sendo cada vez mais refinadas com o crescente uso dos Sistemas de Informação Geográfica (SIG). De forma reducionista, podemos admitir que um simples mapa seja um SI G ${ }^{22}$. Tecnicamente, com o avanço das tecnologias de computação, o termo SIG passou a representar um complexo sistema computacional com possibilidades não apenas deilustrar processos espaciais, mas também realizar análises espaciais usando diferentes bancos de dados de forma integrada.

Para Druck et al. ${ }^{23}$, "o termo Sistemas de Informação Geográfica (SIG) é aplicado para sistemas que realizam o tratamento computacional de dados geográficos earmazenam a geometria e os atributos dos dados que estão georreferenciados, isto é, localizados na superfície terrestre e representados numa projeção cartográfica". Nestes termos, um SI G se mostra capaz de processar dados espaciais com mecanismos de entrada, edição, análise, visualização e saída, ou seja, a manipulação de informações georreferenciadas.

É comum existir uma confusão entre os termos Geoprocessamento eSIG. Geoprocessamento éum termo mais amplo que engloba um conjunto de tecnologias de coleta, tratamento, manipulação e apresentação de dados geográficos, por meio de programas computacionais. Os SIG consistem em apenas uma destas tecnologias dentre várias outras, tais como o sensoriamento remoto, a digitalização de dados, a automação detarefas cartográficas e a utilização de Sistemas de Posicionamento Global - GPS ${ }^{24}$. Geoprocessamento, portanto, éum conjunto deferramentas etecnologias, e o SI G talvez se enquadre como a mais completa técnica de geoprocessamento pela sua capacidade de atuar desde a coleta até a apresentação de informações geográficas.

O uso deSIG está presenteem váriasáreas do conhecimento. Retomando a discussão sobre o conceito de espaço, a utilização de um SI G nada mais é do que a representação computacional do espaço. 0 que configura 0 aspecto transdisciplinar do SI G éjustamentea redução dos mais dife- rentes conceitos de variadas disciplinas em algoritmos e estrutura de dados representados computacionalmente, fazendo com que diferentes áreas do conhecimento utilizem uma linguagem comum do espaço ${ }^{25}$. Paradoxalmente, presenciase a manifestação de diferentes concepções do espaço em um único espaço computacionalmente representado.

O SIG oferece a possibilidade de convergência de diferentes concepções do mundo real em uma única representação espacial, ao mesmo tempo em que não prejudica ou altera os fundamentos e os pressupostos destas diferentes concepções. Isto ocorre porque a representação computacional do espaço, ao contrário das outras representações anteriormente discutidas, não é um fim em si mesmo ou uma premissa filosófica, mas um meio de manifestação dos diferentes conceitos. Esta propriedade garante uma aparenteneutralidade deseu uso (mas não uma neutralidade do usuário), permitindo sua utilização em diferentes campos do saber.

A limitação desse tipo de representação do espaço é inerente à capacidade de transformar diferentes conceitos em linguagens computacionais. Muitas vezes essa transformação não é possível, dada a complexidade do mundo real, mas garante uma aproximação parcial de suas dimensões ${ }^{26}$.

A grande conquista proporcionada pelo avanço das técnicas de geo processamento, em especial os SIG, foi a dinamização dos estáticos mapas de papel. Os SIG trabalham com dois tipos de dados: dados espaciais (dados cartográficos como pontos, linhas e polígonos) edados deatributos (não-gráficos como as tabelas). Os dados espaciais são os objetos gráficos do mapa, tais como os setores censitários, ruas, redes fluviais, cidades, localização de unidades de saúde, casos de uma doença etc. Os dados de atributos são um conjunto deinformações (não espaciais) que se relacionam com os dados espaciais, tais como a população de um território, o clima, o perfil socioeconômico de uma região, o registro clínico-epidemiológico de um caso de uma doença e número de pessoas atendidas em uma unidade desaúde, por exemplo. A existência deuma referência geográfica comum a esses dois tipos de dados permite a localização espacial dos atributos não espaciais ${ }^{27}$.

Dessa maneira, retomando o objeto de estudo da Epidemiologia, ou seja, a distribuição de doenças e agravos em coletividades humanas, e o fato de que todos os eventos de saúde (nascimento, a infecção, 0 adoecimento e a morte) se 
manifestam em pessoas ${ }^{28}$, se obtivermos uma referência geográfica destas pessoas, seja como um dado individual seja como um dado coletivo, será possível localizar os casos de uma doença ou mesmo seus fatores relacionados, vislumbrando o que poderia ser chamado de uma Epidemiologia Georreferenciada.

0 georreferenciamento de um atributo nada mais é do que a sua informação geográfica em termos de posicionamento na superfície terrestre. D essa forma, ao fazermos essa referência geográfica sobre os elementos do processo saúdedoença ( pessoas, serviços de saúde, agentes condicionantes), ultrapassamos a fronteira do corpo biológico e alcançamos uma dimensão mais próxima do que seria um corpo socioespacial, já que a doença passaria a habitar não só as pessoas, mas todo o território que, como já discutido anteriormente, é um aspecto constitutivo desse processo.

N esse sentido, sabemos que a saúde bucal não éum atributo espacial ou uma característica do território. Porém, temos consciência de que sua realização final se manifesta em pessoas que apresentam diferentes condições de saúde bucal. Sendo assim, ao localizarmos espacialmente a população e seus atributos, dentre eles as condições de saúde bucal, poderemos conhecer a distribuição espacial dessas condições em um determinado território. Dessa forma, elementos abstratos como as condições de vida e saúde da população passam a ter uma posição geográfica sobre a superfície terrestre, propriedade própria de elementos concretos.

O uso de SIG no campo da saúde bucal surge no início da década de 1990, refletindo os avanços das técnicas de geoprocessamento em sistemas computacionais acessíveis para diversos tipos de usuários. White et al. ${ }^{29}$ já destacavam, em 2000, o uso do SI G em investigações sobre serviços odontológicos, destacando a possibilidadede visualização espacial de diferentes tipos de informação, dentre eles: a) provisão de serviços odontológicos e a população com necessidade de tratamento; b) distribuição espacial de pessoas com determinada patologia oral e o local de diagnóstico e tratamento e; c) distribuição espacial de um centro de saúde e a proporção de usuários em diferentes raios de distância dessecentro, além da possibilidade de gerar informação para diferentes categorias sociodemográficas.

Morgan e Treasure ${ }^{30}$, utilizando um SIG, mapearam a prevalência decáriee o fornecimento de água de abastecimento público no País de Gales, em 2003. A partir desse mapeamento, foi possível identificar áreas prioritárias para a fluoretação das águas de abastecimento.

No Brasil, ainda são escassos os estudos em saúde bucal queempregam al gum tipo de análise espacial. Antunes et al. ${ }^{31}$ realizaram um estudo epidemiológico testando a associação entre cárie enecessidade de tratamento em crianças de 5 e 12 anos de idade, em diferentes áreas da cidade de São Paulo. Foi observado que as crianças nos distritos centrais da cidade apresentaram menores prevalências de cárie e de necessidade de tratamento quando comparadas às crianças nas áreas periféricas da cidade. Também foi observada uma correlação entre as áreas com piores indicadores sociais (renda familiar, taxa de desemprego, número de pessoas por cômodo na residência eum índice deiniqüidade da distribuição de renda) e maior prevalência de cárie. Distritos com maior privação social apresentaram maior risco para a cárie.

M oreira ${ }^{32}$ investigou, em um estudo transversal, as condições de saúde bucal de uma amostra aleatória de 372 idosos domiciliados na área urbana de Botucatu - SP, no ano de 2005, ea distribuição espacial destas condições. Com auxílio de um SIG, foi realizada uma análise espacial objetivando a construção de mapas deKernel (Kernel estimation). Esteprocedimento visa compor uma superfície contínua, a partir de dados discretos, cujo valor será proporcional à intensidade de amostras por unidade de área. Os resultados evidenciaram uma marginalização das piores condições bucais, assim como de outras variáveis, tais como a renda ea escolaridade, contrastando com o padrão de distribuição central dos melhores indicadores bucais e socioeconômicos.

Em Curitiba, M oysés et al. ${ }^{33}$ avaliaram a experiência de trauma dentário em escolares de 12 anos e a distribuiç̧ão geográfica desse evento, investigando associações com aspectos físicos e sociais de áreas da cidade. A pós o geoprocessamento dos dados, utilizando para este fim um SIG, foi constatado que as regiões norte e leste apresentaram maior prevalência detraumas dentários. Aspectos geográficos, físicos e de implementação de políticas públicas, caracterizados como fatores contextuais, mostraram-se associados às diferenças intra-urbanas na prevalência de trauma dentário na cidade de Curitiba.

É importante ressaltar que a saúde bucal não se resume às suas características clínico-epidemiológicas, mas abrange toda uma complexa rede de circunstâncias e atores sociais, tais como o cirurgião-dentista, a equipe auxiliar, o paciente 
etoda uma conjuntura política, atuantes no processo saúde-doença bucal e passíveis de serem georreferenciados.

Com efeito, a saúde bucal georreferenciada não preten de ignorar a categoria social do homem, pois a intenção não é separá-la do sujeito, mas revelar o comportamento espacial de suas diversas dimensões, incluindo sua dimensão social.

Como todo recorte da realidade, a análise de dados espaciais em saúde é um modelo reducionista, mas representa uma al ternativa viável para a compreensão do processo saúde doença, dada a impossibilidade de uma apreensão totalizante da realidade.

A viabilização de análises espaciais em saúde, especialmente em saúde bucal, requer maior aprofundamento teórico quanto aos tipos de metodologias que podem ser empregadas, a disponibilidade de informações em saúde bucal ea sua cobertura territorial, assim como o tipo de referência e escala geográfica que tais informações permitem. Além disso, torna-se necessária maior consciência sobre a importância do espaço na Saúde Bucal Coletiva por parte da comunidade científica, dos gestores públicos e da própria população, a fim de fomentar a produção de conhecimento nessa área.

Entretanto, a execução de análises espaciais em saúde bucal depende da disponibilidade de informações epidemiológicas de base populacional, incluindo informações geográficas desses dados e a existência de uma base cartográfica digital do território abordado. 0 Instituto Brasileiro de Geografia e Estatística (IBGE) disponibiliza malhas digitais dos setores censitários dos municípios brasileiros, porém não há informações sobre as ruas ou códigos de endereçamento postal. Aparelhos de GPS, apesar de elevar o custo da pesquisa, poderiam ser utilizados para registrar a posição dos elementos investigados (residências, unidades de saúde, escolas). Além disso, os custos para a aquisição de programas computacionais e a qualificação de profissionais também consistem em obstáculos para a implementação de SIG no campo da saúde pública. Porém, a ten dência na criação de softwares livres e gratuitos, como, por exemplo, o TerraView e o Spring (ambos desenvolvidos pelo Instituto Nacional de Pesquisas Espaciais) e a crescente proliferação de cursos e 0 aumento na produção científica sobre análise espacial em saúde vêm contribuindo para a redução desses obstáculos. Em todo o caso, a realização de parcerias e a capacitação de recursos humanos são fundamentais para a viabilidade de projetos, tanto acadêmicos quanto de serviços públicos de saúde que utilizam SIG.

\section{Consideraçõesfinais}

A diferenciação espacial dentro de um determinado território sugere diferentes formas de organização da infra-estrutura, oferta e local ização de serviços de saúde, presença de equipamentos sociais, dentre uma série de outras características que refletem a construção político-social do espaço geográfico, evidenciando, assim, a reprodução dos processos presentes no modo de produção capitalista.

Com efeito, o que se propõe com a análise da influência espacial no processo saúde-doença é reduzir as distâncias que resultam em dicotomia entre estudos agregados e estudos "individuados", buscando analisar simultaneamente dados individuais associados a dados ecológicos (agregados). N este caso, estaremos trabal hando com mais de uma unidade de observação. Todavia, sendo os dados individuais uma amostra representativa da coletividade populacional, ao final o que se observa engloba a matéria-prima da investigação epidemiológica, ou seja, conjuntos formados por indivíduos.

No que diz respeito à saúde bucal coletiva, 0 estudo das condições de saúde bucal e seus determinantes são passíveis de serem referenciados geograficamente.

Além dessa importante contribuição para o entendimento do processo saúde-doença bucal, a localização geográfica dos diferentes componentes desse processo permite o planejamento de ações de promoção, controle e reabilitação o mais próximo possível das áreas atingidas, obedecendo, assim, aos princípios do Sistema Ú nico deSaúde(SUS) dedescentralização e territorialização dos cuidados com a saúde.

A "espacial ização da população" e, conseqüentemente, de suas condições de vida e saúde, possibilita ampliar a compreensão da distribuição das iniqüidades em saúde. 0 padrão de ocupação e uso desse território, antes de ser apenas uma questão geográfica, reflete os complexos processos históricos e sociais presentes nas coletividades humanas. A marginalização da pobreza ea centralização da riqueza, tanto em aspectos sociais quanto em aspectos de saúde bucal, além de representarem uma diferença na posição geográfica, representam também uma diferença na posição social. 
No entanto, a compreensão da relação saúde doença-território podeocorrer de várias maneiras. A descrição dessa relação é uma delas. Outros desenhos com maior potencial estatístico analítico, assim como a realização de pesqui- sas com metodologias qualitativas de apreensão dessa relação, surgem como propostas complementares para a elucidação dos complexos eventos presentes no palco do mundo real: o território.

\section{Colaboradores}

RS M oreira foi responsável pela idealização eelaboração do artigo. LS Nico auxiliou na revisão e formatação do artigo. NE Tomita foi responsável pela revisão do artigo.

\section{Agradecimentos}

Este trabalho teve 0 apoio da Fundação de Amparo à Pesquisa do Estado de São Paulo (FAPESP processo n. 04/03629-8).

\section{Referências}

1. Medronho RA, Perez MA. Distribuição das doenças no espaço e no tempo. In: M edronho RA, Carvalho DM, Bloch KV, Luiz RR, Werneck GL. Epide miologia. São Paulo: Atheneu; 2004. p. 57-71.

2. Snow J. Sobre a maneira de transmissão de cólera. São Paulo: Hucitec-Abrasco; 1990.

3. Rothman KJ, Greenland S. Modern epidemiology. Philadelphia, PA: Lippincott-Raven; 1998.

4. Almeida-Filho N. A ciência da saúde. São Paulo: Hucitec; 2000.

5. Breilh L, Granda E. Investigação da saúde na socie dade: guia pedagógico sobre um novo enfoque do mé todo epidemiológico. São Paulo: Abrasco; 1986.

6. Costa MCN, Teixeira M GLC. A concepção de "espaço" na investigação epidemiológica. Cad Saúde Pública 1999; 15(2): 271-279.

7. Moysés SJ, Sheiham A. Saúde bucal coletiva: personagens, autores ou... Pirandello de novo? In: Kriger $L$, organizador. ABOPREV: promoção de saúde bucal. São Paulo: Artes M édicas; 2003. p. 387-442.

8. Pino A. A categoria de "espaço" em psicologia. In: Miguel A, Zamboni E, organizadores. Representações do espaço: multidisciplinaridade na educação. Campinas: Autores Associados; 1996. p. 51-68.

9. Gutierre JHB. Notas introdutórias à discussão do conceito kantiano de espaço. In: Miguel A, Zamboni $E$, organizadores. Representações do espaço: multidisciplinaridade na educação. Campinas: Autores Associados; 1996. p. 31-50.

10. Miceli P. A terceira margem - notas breves sobre a representação do espaço no trabalho do historiador. In: Miguel A, Zamboni E, organizadores. Representações do espaço: multidisciplinaridade na educação. Campinas: Autores Associados; 1996. p. 9-15.

11. Czeresnia D, Ribeiro AM . O conceito de espaço em epidemiologia: uma interpretação histórica e epidemiológica. Cad Saúde Pública 2000; 16(3): 595-617.

12. Barrios S. A produção do espaço. In: Souza MAA, Santos $M$, organizadores. A construção do espaço. São Paulo: Nobel; 1986. p. 1-24. 
13. Donnangelo M CF. Saúde e Sociedade. São Paulo: Duas Cidades; 1979.

14. Weyne SG. A construção do paradigma de promoção de saúde - um desafio para as novas gerações. In: Kriger L, organizador. ABOPREV: promoção de saúde bucal. São Paulo: Artes M édicas; 2003. p. 1-23.

15. Susser M, Susser E. Choosing a future for Epidemiology: II. From black box to Chinese boxes and ecoepidemiology. Am J Public Health 1996; 86: 674-7.

16. Krieger N. Epidemiology and the web of causation: has anyone seen the spiders? Soc Sci M ed 1994; 39: 887-903.

17. Marques E, Torres H. São Paulo: segregação, pobreza e desigualdades sociais. São Paulo: Senac; 2005.

18. M onken $M$, Barcellos $C$. Vigilância em saúde e território utilizado: possibilidades teóricas e metodológicas. Cad Saúde Pública 2005; 21: 898-906.

19. Gomes S, Amitrano C. Local de moradia na metrópole e vulnerabilidade ao (emprego e desemprego). In: Marques E, Torres $H$, organizadores. São Paulo: segregação, pobreza e desigualdades sociais. São Paulo: Senac; 2005. p. 169-94.

20. M CPhail CWB, Grainger RM. A mapping procedure for the geographic pathology of dental caries. Int Dent J 1969; 19: 380-92.

21. Ayres JR. Debate sobre o artigo de Dina Czeresnia \& Adriana Maria Ribeiro. Cad Saúde Pública 2000; 16: 610-611.

22. Torres H. Anexo metodológico: SIG e análise sociodemográfica. In: Marques $\mathrm{E}$, Torres $\mathrm{H}$, organizadores. São Paulo: segregação, pobreza e desigualdades sociais. São Paulo: Senac; 2005. p. 315-20.

23. Druck S, Carvalho MS, Câmara G, Monteiro AM V, organizadores. Análise espacial de dados geográficos. Planaltina: Empresa Brasileira de Pesquisa Agropecuária; 2004.

24. Santos SM, Pina M F, Carvalho MS. Os sistemas de informações geográficas. In: Carvalho MS, Pina MF, Santos SM , organizadores. Conceitos básicos de sistemas de informação geográfica e cartografia aplicados à saúde. Brasília: M inistério da Saúde; 2000. p. 13-39.
25. Câmara G, M onteiro AM V. Conceitos básicos da ciência da geoinformação. In: Câmara G, Davis C, M onteiro AM V, organizadores. Introdução à ciência da geoinformação. [acessado 2005 Out 19]. Disponível em: http://www.dpi.inpe.br/gilberto/livro/ introd

26. Câmara G, M onteiro AM V, M edeiros JS. Fundamentos epistemológicos da ciência da geoinformação. In: Câmara G, Davis C, M onteiro AM V, organizadores. Introdução à ciência da geoinformação. [acessado 2005 Out 19]. Disponível em: http:// www.dpi.inpe.br/gilberto/livro/introd

27. Organização Pan-Americana de Saúde. Sistemas de informação geográfica em saúde: conceitos básicos. Brasília: Organização Pan-Americana de Saúde; 2002.

28. Barcellos C. A saúde nos sistemas de informação geográfica: apenas uma camada a mais? Cad Prudentino Geogr 2003; 25: 29-43.

29. White DA, Anderson RJ, Bradnock G, Gray M M, Jenkins $P$. The use of a geographical information system in investigating dental services. Community Dent $\mathrm{H}$ ealth 2000; 17: 79-84.

30. Morgan MZ, Treasure ET. M apping caries prevalence and water distribution in Wales - lechyd Morgannwg Health Authority as a case study. Community Dent Health 2003; 20: 94-9.

31. Antunes JLF, Frazão P, Narvai PC, Bispo CM, Pegoretti $T$. Spatial analysis to identify differentials in dental needs by area-based measures. Community Dent Oral Epidemiol 2002; 30: 133-42.

32. M oreira RS. A saúde bucal de idosos e a sua descrição espacial: a epidemiologia georreferenciada [dissertação]. Botucatu (SP): Universidade Estadual Paulista; 2005.

33. M oysés SJ, M oysés ST, Camillotti A. Análise espacial do trauma dentário em escolares de 12 anos em Curitiba, PR. [CD-ROM ]. In: Anais do VI Congresso Brasileiro de Epidemiologia; 2004; Recife.

Artigo apresentado em 7/11/2005

Aprovado em 30/01/2006

Versão final apresentada em 15/03/2006 